\title{
Fixed point results for Meir-Keeler-type $\phi-\alpha$-contractions on partial metric spaces
}

\section{Chao-Hung Chen ${ }^{1}$ and Chi-Ming Chen ${ }^{2 *}$}

\section{"Correspondence:}

ming@mail.nhcue.edu.tw

${ }^{2}$ Department of Applied

Mathematics, National Hsinchu

University of Education, Hsinchu, Taiwan

Full list of author information is

available at the end of the article

\section{Abstract}

The purpose of this paper is to study fixed point theorems for a mapping satisfying the generalized Meir-Keeler-type $\phi$ - $\alpha$-contractions in complete partial metric spaces. Our results generalize or improve many recent fixed point theorems in the literature.

MSC: 47H10; 54C60; 54H25; 55M20

Keywords: fixed point; $\alpha$-admissible; generalized Meir-Keeler-type $\phi$ - $\alpha$-contraction; partial metric space

\section{Introduction and preliminaries}

Throughout this paper, by $\mathbb{R}^{+}$we denote the set of all nonnegative real numbers, while $\mathbb{N}$ is the set of all natural numbers. In 1994, Mattews [1] introduced the following notion of partial metric spaces.

Definition 1 [1] A partial metric on a nonempty set $X$ is a function $p: X \times X \rightarrow \mathbb{R}^{+}$such that for all $x, y, z \in X$,

$\left(p_{1}\right) \quad x=y$ if and only if $p(x, x)=p(x, y)=p(y, y)$

$\left(p_{2}\right) p(x, x) \leq p(x, y)$;

(p. $p(x, y)=p(y, x)$;

$\left(p_{4}\right) p(x, y) \leq p(x, z)+p(z, y)-p(z, z)$.

A partial metric space is a pair $(X, p)$ such that $X$ is a nonempty set and $p$ is a partial metric on $X$.

Remark 1 It is clear that if $p(x, y)=0$, then from $\left(p_{1}\right)$ and $\left(p_{2}\right), x=y$. But if $x=y, p(x, y)$ may not be 0 .

Each partial metric $p$ on $X$ generates a $\mathcal{T}_{0}$ topology $\tau_{p}$ on $X$ which has as a base the family of open $p$-balls $\left\{B_{p}(x, \gamma): x \in X, \gamma>0\right\}$, where $B_{p}(x, \gamma)=\{y \in X: p(x, y)<p(x, x)+\gamma\}$ for all $x \in X$ and $\gamma>0$. If $p$ is a partial metric on $X$, then the function $d_{p}: X \times X \rightarrow \mathbb{R}^{+}$given by

$$
d_{p}(x, y)=2 p(x, y)-p(x, x)-p(y, y)
$$

is a metric on $X$.

We recall some definitions of a partial metric space as follows.

(0) 2013 Chen and Chen; licensee Springer. This is an Open Access article distributed under the terms of the Creative Commons Attribution License (http://creativecommons.org/licenses/by/2.0), which permits unrestricted use, distribution, and reproduction in any medium, provided the original work is properly cited. 
Definition 2 [1] Let $(X, p)$ be a partial metric space. Then

(1) a sequence $\left\{x_{n}\right\}$ in a partial metric space $(X, p)$ converges to $x \in X$ if and only if $p(x, x)=\lim _{n \rightarrow \infty} p\left(x, x_{n}\right) ;$

(2) a sequence $\left\{x_{n}\right\}$ in a partial metric space $(X, p)$ is called a Cauchy sequence if and only if $\lim _{m, n \rightarrow \infty} p\left(x_{m}, x_{n}\right)$ exists (and is finite);

(3) a partial metric space $(X, p)$ is said to be complete if every Cauchy sequence $\left\{x_{n}\right\}$ in $X$ converges, with respect to $\tau_{p}$, to a point $x \in X$ such that $p(x, x)=\lim _{m, n \rightarrow \infty} p\left(x_{m}, x_{n}\right)$;

(4) a subset $A$ of a partial metric space $(X, p)$ is closed if whenever $\left\{x_{n}\right\}$ is a sequence in $A$ such that $\left\{x_{n}\right\}$ converges to some $x \in X$, then $x \in A$.

Remark 2 The limit in a partial metric space is not unique.

Lemma $1[1,2]$

(1) $\left\{x_{n}\right\}$ is a Cauchy sequence in a partial metric space $(X, p)$ if and only if it is a Cauchy sequence in the metric space $\left(X, d_{p}\right)$;

(2) a partial metric space $(X, p)$ is complete if and only if the metric space $\left(X, d_{p}\right)$ is complete. Furthermore, $\lim _{n \rightarrow \infty} d_{p}\left(x_{n}, x\right)=0$ if and only if $p(x, x)=\lim _{n \rightarrow \infty} p\left(x_{n}, x\right)=\lim _{n \rightarrow \infty} p\left(x_{n}, x_{m}\right)$.

In recent years, fixed point theory has developed rapidly on partial metric spaces, see [2-10].

In this study, we also recall the Meir-Keeler-type contraction [11] and $\alpha$-admissible one [12]. In 1969, Meir and Keeler [11] introduced the following notion of Meir-Keeler-type contraction in a metric space $(X, d)$.

Definition 3 Let $(X, d)$ be a metric space, $f: X \rightarrow X$. Then $f$ is called a Meir-Keeler-type contraction whenever, for each $\eta>0$, there exists $\gamma>0$ such that

$$
\eta \leq d(x, y)<\eta+\gamma \quad \Longrightarrow \quad d(f x, f y)<\eta .
$$

The following definition was introduced in [12].

Definition 4 Let $f: X \rightarrow X$ be a self-mapping of a set $X$ and $\alpha: X \times X \rightarrow \mathbb{R}^{+}$. Then $f$ is called $\alpha$-admissible if

$$
x, y \in X, \quad \alpha(x, y) \geq 1 \quad \Longrightarrow \quad \alpha(f x, f y) \geq 1 .
$$

The purpose of this paper is to study fixed point theorems for a mapping satisfying the generalized Meir-Keeler-type $\phi$ - $\alpha$-contractions in complete partial metric spaces. Our results generalize or improve many recent fixed point theorems in the literature.

\section{Main results}

In the article, we denote by $\Phi$ the class of functions $\phi: \mathbb{R}^{+4} \rightarrow \mathbb{R}^{+}$satisfying the following conditions:

$\left(\phi_{1}\right) \phi$ is an increasing and continuous function in each coordinate;

$\left(\phi_{2}\right)$ for $t \in \mathbb{R}^{+} \backslash\{0\}, \phi(t, t, t, t) \leq t, \phi(t, 0,0, t) \leq t, \phi\left(0,0, t, \frac{t}{2}\right) \leq t$; and $\phi\left(t_{1}, t_{2}, t_{3}, t_{4}\right)=0$ iff $t_{1}=t_{2}=t_{3}=t_{4}=0$. 
We now state the new notions of generalized Meir-Keeler-type $\phi$-contractions and generalized Meir-Keeler-type $\phi$ - $\alpha$-contractions in partial metric spaces as follows.

Definition 5 Let $(X, p)$ be a partial metric space, $f: X \rightarrow X$ and $\phi \in \Phi$. Then $f$ is called a generalized Meir-Keeler-type $\phi$-contraction whenever, for each $\eta>0$, there exists $\delta>0$ such that

$$
\begin{aligned}
\eta & \leq \phi\left(p(x, y), p(x, f x), p(y, f y), \frac{1}{2}[p(x, f y)+p(y, f x)]\right)<\eta+\delta \\
& \Longrightarrow \quad p(f x, f y)<\eta .
\end{aligned}
$$

Definition 6 Let $(X, p)$ be a partial metric space, $f: X \rightarrow X, \phi \in \Phi$ and $\alpha: X \times X \rightarrow \mathbb{R}^{+}$. Then $f$ is called a generalized Meir-Keeler-type $\phi$ - $\alpha$-contraction if the following conditions hold:

(1) $f$ is $\alpha$-admissible;

(2) for each $\eta>0$, there exists $\delta>0$ such that

$$
\begin{aligned}
\eta & \leq \phi\left(p(x, y), p(x, f x), p(y, f y), \frac{1}{2}[p(x, f y)+p(y, f x)]\right)<\eta+\delta \\
& \Longrightarrow \quad \alpha(x, x) \alpha(y, y) p(f x, f y)<\eta .
\end{aligned}
$$

Remark 3 Note that if $f$ is a generalized Meir-Keeler-type $\phi$ - $\alpha$-contraction, then we have that for all $x, y \in X$,

$$
\begin{aligned}
& \alpha(x, x) \alpha(y, y) p(f x, f y) \\
& \quad \leq \phi\left(p(x, y), p(x, f x), p(y, f y), \frac{1}{2}[p(x, f y)+p(y, f x)]\right) .
\end{aligned}
$$

Further, if $\phi\left(p(x, y), p(x, f x), p(y, f y), \frac{1}{2}[p(x, f y)+p(y, f x)]\right)=0$, then $p(f x, f y)=0$. On the other hand, if $\phi\left(p(x, y), p(x, f x), p(y, f y), \frac{1}{2}[p(x, f y)+p(y, f x)]\right)>0$, then $\alpha(x, x) \alpha(y, y) p(f x, f y)<$ $\phi\left(p(x, y), p(x, f x), p(y, f y), \frac{1}{2}[p(x, f y)+p(y, f x)]\right)$.

We now state our main result for the generalized Meir-Keeler-type $\phi$ - $\alpha$-contraction as follows.

Theorem 1 Let $(X, p)$ be a complete partial metric space, and $\phi \in \Phi$. If $\alpha: X \times X \rightarrow \mathbb{R}^{+}$ satisfies the following conditions:

$\left(\alpha_{1}\right)$ there exists $x_{0} \in X$ such that $\alpha\left(x_{0}, x_{0}\right) \geq 1$;

$\left(\alpha_{2}\right)$ if $\alpha\left(x_{n}, x_{n}\right) \geq 1$ for all $n \in \mathbb{N}$, then $\lim _{n \rightarrow \infty} \alpha\left(x_{n}, x_{n}\right) \geq 1$;

$\left(\alpha_{3}\right) \alpha: X \times X \rightarrow \mathbb{R}^{+}$is a continuous function in each coordinate.

Suppose that $f: X \rightarrow X$ is a generalized Meir-Keeler-type $\phi$ - $\alpha$-contraction. Then $f$ has a fixed point in $X$.

Proof Let $x_{0}$ and let $x_{n+1}=f x_{n}=f^{n} x_{0}$ for $n=0,1,2, \ldots$ Since $f$ is $\alpha$-admissible and $\alpha\left(x_{0}, x_{0}\right) \geq 1$, we have

$$
\alpha\left(f x_{0}, f x_{0}\right)=\alpha\left(x_{1}, x_{1}\right) \geq 1 .
$$


By continuing this process, we get

$$
\alpha\left(x_{n}, x_{n}\right) \geq 1 \quad \text { for all } n \in \mathbb{N} \cup\{0\}
$$

If there exists $n_{0} \in \mathbb{N}$ such that $x_{n_{0}+1}=x_{n_{0}}$, then we finished the proof. Suppose that $x_{n+1} \neq x_{n}$ for any $n=0,1,2, \ldots$. By the definition of the function $\phi$, we have $\phi\left(p\left(x_{n}, x_{n+1}\right), p\left(x_{n}, f x_{n}\right), p\left(x_{n+1}, f x_{n+1}\right), \frac{1}{2}\left[p\left(x_{n}, f x_{n+1}\right)+p\left(x_{n+1}, f x_{n}\right)\right]\right)>0$ for all $n \in \mathbb{N} \cup\{0\}$.

Step 1 . We shall prove that

$$
\lim _{n \rightarrow \infty} p\left(x_{n}, x_{n+1}\right)=0, \quad \text { that is } \lim _{n \rightarrow \infty} d_{p}\left(x_{n}, x_{n+1}\right)=0 \text {. }
$$

By Remark 3 and $\left(p_{4}\right)$, using (2.2), we have

$$
\begin{aligned}
p\left(x_{n+1}, x_{n+2}\right) \\
\quad=p\left(f x_{n}, f x_{n+1}\right) \\
\quad \leq \alpha\left(x_{n}, x_{n}\right) \alpha\left(x_{n+1}, x_{n+1}\right) p\left(f x_{n}, f x_{n+1}\right) \\
\quad<\phi\left(p\left(x_{n}, x_{n+1}\right), p\left(x_{n}, f x_{n}\right), p\left(x_{n+1}, f x_{n+1}\right), \frac{1}{2}\left[p\left(x_{n}, f x_{n+1}\right)+p\left(x_{n+1}, f x_{n}\right)\right]\right) \\
\quad=\phi\left(p\left(x_{n}, x_{n+1}\right), p\left(x_{n}, x_{n+1}\right), p\left(x_{n+1}, x_{n+2}\right), \frac{1}{2}\left[p\left(x_{n}, x_{n+2}\right)+p\left(x_{n+1}, x_{n+1}\right)\right]\right) \\
\quad \leq \phi\left(p\left(x_{n}, x_{n+1}\right), p\left(x_{n}, x_{n+1}\right), p\left(x_{n+1}, x_{n+2}\right), \frac{1}{2}\left[p\left(x_{n}, x_{n+1}\right)+p\left(x_{n+1}, x_{n+2}\right)\right]\right) .
\end{aligned}
$$

If $p\left(x_{n}, x_{n+1}\right) \leq p\left(x_{n+1}, x_{n+2}\right)$, then

$$
\begin{aligned}
p\left(x_{n+1}, x_{n+2}\right) & =p\left(f x_{n}, f x_{n+1}\right) \\
& <\phi\left(p\left(x_{n+1}, x_{n+2}\right), p\left(x_{n+1}, x_{n+2}\right), p\left(x_{n+1}, x_{n+2}\right), p\left(x_{n+1}, x_{n+2}\right)\right) \\
& \leq p\left(x_{n+1}, x_{n+2}\right),
\end{aligned}
$$

which implies a contradiction, and hence $p\left(x_{n}, x_{n+1}\right)<p\left(x_{n-1}, x_{n}\right)$. From the argument above, we also have that for each $n \in \mathbb{N}$,

$$
\begin{aligned}
p\left(x_{n+1}, x_{n+2}\right) & =p\left(f x_{n}, f x_{n+1}\right) \\
& <\phi\left(p\left(x_{n}, x_{n+1}\right), p\left(x_{n}, x_{n+1}\right), p\left(x_{n}, x_{n+1}\right), p\left(x_{n}, x_{n+1}\right)\right) \\
& \leq p\left(x_{n}, x_{n+1}\right) .
\end{aligned}
$$

Since the sequence $\left\{p\left(x_{n}, x_{n+1}\right)\right\}$ is decreasing, it must converge to some $\eta \geq 0$, that is,

$$
\lim _{n \rightarrow \infty} p\left(x_{n}, x_{n+1}\right)=\eta
$$

It follows from (2.4) and (2.5) that

$$
\lim _{n \rightarrow \infty} \phi\left(p\left(x_{n}, x_{n+1}\right), p\left(x_{n}, x_{n+1}\right), p\left(x_{n}, x_{n+1}\right), p\left(x_{n}, x_{n+1}\right)\right)=\eta .
$$


Notice that $\eta=\inf \left\{p\left(x_{n}, x_{n+1}\right): n \in \mathbb{N}\right\}$. We claim that $\eta=0$. Suppose, to the contrary, that $\eta>0$. Since $f$ is a generalized Meir-Keeler-type $\phi$-contraction, corresponding to $\eta$ use, and taking into account the above inequality (2.6), there exist $\delta>0$ and a natural number $k$ such that

$$
\begin{aligned}
\eta & \leq \phi\left(p\left(x_{k}, x_{k+1}\right), p\left(x_{k}, x_{k+1}\right), p\left(x_{k}, x_{k+1}\right), p\left(x_{k}, x_{k+1}\right)\right)<\eta+\delta \\
& \Longrightarrow \alpha\left(x_{k}, x_{k}\right) \alpha\left(x_{k+1}, x_{k+1}\right) p\left(f x_{k}, f x_{k+1}\right)<\eta
\end{aligned}
$$

which implies

$$
p\left(x_{k+1}, x_{k+2}\right)=p\left(f x_{k}, f x_{k+1}\right) \leq \alpha\left(x_{k}, x_{k}\right) \alpha\left(x_{k+1}, x_{k+1}\right) p\left(f x_{k}, f x_{k+1}\right)<\eta
$$

So, we get a contradiction since $\eta=\inf \left\{p\left(x_{n}, x_{n+1}\right): n \in \mathbb{N}\right\}$. Thus we have that

$$
\lim _{n \rightarrow \infty} p\left(x_{n}, x_{n+1}\right)=0
$$

By $\left(p_{2}\right)$, we also have

$$
\lim _{n \rightarrow \infty} p\left(x_{n}, x_{n}\right)=0
$$

Since $d_{p}(x, y)=2 p(x, y)-p(x, x)-p(y, y)$ for all $x, y \in X$, using (2.7) and (2.8), we obtain that

$$
\lim _{n \rightarrow \infty} d_{p}\left(x_{n}, x_{n+1}\right)=0
$$

Step 2. We show that $\left\{x_{n}\right\}$ is a Cauchy sequence in the partial metric space $(X, p)$, that is, it is sufficient to show that $\left\{x_{n}\right\}$ is a Cauchy sequence in the metric space $\left(X, d_{p}\right)$.

Suppose that the above statement is false. Then there exists $\epsilon>0$ such that for any $k \in \mathbb{N}$, there are $n_{k}, m_{k} \in \mathbb{N}$ with $n_{k}>m_{k} \geq k$ satisfying

$$
d_{p}\left(x_{m_{k}}, x_{n_{k}}\right) \geq \epsilon
$$

Further, corresponding to $m_{k} \geq k$, we can choose $n_{k}$ in such a way that it is the smallest integer with $n_{k}>m_{k} \geq k$ and $d\left(x_{2 m_{k}}, x_{2 n_{k}}\right) \geq \epsilon$. Therefore

$$
d_{p}\left(x_{m_{k}}, x_{n_{k}-2}\right)<\epsilon
$$

Now we have that for all $k \in \mathbb{N}$,

$$
\begin{aligned}
\epsilon & \leq d_{p}\left(x_{m_{k}}, x_{n_{k}}\right) \\
& \leq d_{p}\left(x_{m_{k}}, x_{n_{k}-2}\right)+d_{p}\left(x_{n_{k}-2}, x_{n_{k}-1}\right)+d_{p}\left(x_{n_{k}-1}, x_{n_{k}}\right) \\
& <\epsilon+d_{p}\left(x_{n_{k}-2}, x_{n_{k}-1}\right)+d_{p}\left(x_{n_{k}-1}, x_{n_{k}}\right) .
\end{aligned}
$$

Letting $k \rightarrow \infty$ in the above inequality and using (2.12), we get

$$
\lim _{n \rightarrow \infty} d_{p}\left(x_{m_{k}}, x_{n_{k}}\right)=\epsilon
$$


On the other hand, we have

$$
\begin{aligned}
\epsilon & \leq d_{p}\left(x_{m_{k}}, x_{n_{k}}\right) \\
& \leq d_{p}\left(x_{m_{k}}, x_{m_{k+1}}\right)+d_{p}\left(x_{m_{k+1}}, x_{n_{k+1}}\right)+d_{p}\left(x_{n_{k+1}}, x_{n_{k}}\right) \\
& \leq d_{p}\left(x_{m_{k}}, x_{m_{k+1}}\right)+d_{p}\left(x_{m_{k+1}}, x_{m_{k}}\right)+d_{p}\left(x_{m_{k}}, x_{n_{k}}\right)+d_{p}\left(x_{n_{k}}, x_{n_{k+1}}\right)+d_{p}\left(x_{n_{k+1}}, x_{n_{k}}\right) .
\end{aligned}
$$

Letting $n \rightarrow \infty$, we obtain that

$$
\lim _{n \rightarrow \infty} d_{p}\left(x_{m_{k+1}}, x_{n_{k+1}}\right)=\epsilon
$$

Since $d_{p}(x, y)=2 p(x, y)-p(x, x)-p(y, y)$ and using (2.13) and (2.14), we have that

$$
\lim _{n \rightarrow \infty} p\left(x_{m_{k}}, x_{n_{k}}\right)=\frac{\epsilon}{2}
$$

and

$$
\lim _{n \rightarrow \infty} p\left(x_{m_{k+1}}, x_{n_{k+1}}\right)=\frac{\epsilon}{2}
$$

By Remark 3 and $\left(p_{4}\right)$, we have

$$
\begin{aligned}
& p\left(x_{m_{k+1}}, x_{n_{k+1}}\right) \\
&= p\left(f x_{m_{k}}, f x_{n_{k}}\right) \\
& \leq \alpha\left(x_{m_{k}}, x_{m_{k}}\right) \alpha\left(x_{n_{k}}, x_{n_{k}}\right) p\left(f x_{m_{k}}, f x_{n_{k}}\right) \\
&< \phi\left(p\left(x_{m_{k}}, x_{n_{k}}\right), p\left(x_{m_{k}}, f x_{m_{k}}\right), p\left(x_{n_{k}}, f x_{n_{k}}\right), \frac{1}{2}\left[p\left(x_{m_{k}}, f x_{n_{k}}\right)+p\left(x_{n_{k}}, f x_{m_{k}}\right)\right]\right) \\
&= \phi\left(p\left(x_{m_{k}}, x_{n_{k}}\right), p\left(x_{m_{k}}, x_{m_{k}+1}\right), p\left(x_{n_{k}}, x_{n_{k+1}}\right),\right. \\
&\left.\frac{1}{2}\left[p\left(x_{m_{k}}, x_{n_{k}+1}\right)+p\left(x_{n_{k}}, x_{m_{k}+1}\right)\right]\right) .
\end{aligned}
$$

Since

$$
p\left(x_{m_{k}}, x_{n_{k}+1}\right) \leq p\left(x_{m_{k}}, x_{m_{k}+1}\right)+p\left(x_{m_{k}+1}, x_{n_{k}+1}\right)-p\left(x_{m_{k}+1}, x_{m_{k}+1}\right)
$$

and

$$
p\left(x_{n_{k}}, x_{m_{k}+1}\right) \leq p\left(x_{n_{k}}, x_{n_{k}+1}\right)+p\left(x_{n_{k}+1}, x_{m_{k}+1}\right)-p\left(x_{n_{k}+1}, x_{n_{k}+1}\right) .
$$

Taking into account the above inequalities (2.8), (2.17), (2.18) and (2.19), letting $k \rightarrow \infty$, we have

$$
\frac{\epsilon}{2}<\phi\left(\frac{\epsilon}{2}, 0,0, \frac{\epsilon}{2}\right) \leq \frac{\epsilon}{2},
$$

which implies a contradiction. Thus, $\left\{x_{n}\right\}$ is a Cauchy sequence in the metric space $\left(X, d_{p}\right)$. 
Step 3. We show that $f$ has a fixed point $v$ in $\bigcap_{i=1}^{m} A_{i}$.

Since $(X, p)$ is complete, then from Lemma 1 , we have that $\left(X, d_{p}\right)$ is complete. Thus, there exists $v \in X$ such that

$$
\lim _{n \rightarrow \infty} d_{p}\left(x_{n}, v\right)=0
$$

Moreover, it follows from Lemma 1 that

$$
p(\nu, v)=\lim _{n \rightarrow \infty} p\left(x_{n}, v\right)=\lim _{n, m \rightarrow \infty} p\left(x_{n}, x_{m}\right) .
$$

On the other hand, since the sequence $\left\{x_{n}\right\}$ is a Cauchy sequence in the metric space $\left(X, d_{p}\right)$, we also have

$$
\lim _{n \rightarrow \infty} d_{p}\left(x_{n}, x_{m}\right)=0 .
$$

Since $d_{p}(x, y)=2 p(x, y)-p(x, x)-p(y, y)$, we can deduce that

$$
\lim _{n \rightarrow \infty} p\left(x_{n}, x_{m}\right)=0
$$

Using (2.20) and (2.21), we have

$$
p(v, v)=\lim _{n \rightarrow \infty} p\left(x_{n}, v\right)=\lim _{n \rightarrow \infty} p\left(x_{n_{k}}, v\right)=0 .
$$

Again, by Remark 3, $\left(p_{4}\right)$, and the conditions of the mapping $\alpha$, we have

$$
\begin{aligned}
p\left(x_{n+1}, f v\right) & =p\left(f x_{n}, f v\right) \\
& \leq \alpha\left(x_{n}, x_{n}\right) \alpha(v, v) p\left(f x_{n}, f v\right) \\
& <\phi\left(p\left(x_{n}, v\right), p\left(x_{n}, f x_{n}\right), p(v, f v), \frac{1}{2}\left[p\left(x_{n}, f v\right)+p\left(v, f x_{n}\right)\right]\right) \\
& =\phi\left(p\left(x_{n}, v\right), p\left(x_{n}, x_{n+1}\right), p(v, f v), \frac{1}{2}\left[p\left(x_{n}, f v\right)+p\left(v, x_{n+1}\right)\right]\right) .
\end{aligned}
$$

Letting $n \rightarrow \infty$ in (2.22), we get

$$
p(v, f v)<\phi\left(0,0, p(v, f v), \frac{1}{2} p(v, f v)\right) \leq p(v, f v),
$$

a contradiction. So, we have $p(v, f v)=0$, that is, $f v=v$.

We give the following example to illustrate Theorem 2 .

Example 1 Let $X=[0,1]$. We define the partial metric $p$ on $X$ by

$$
p(x, y)=\max \{x, y\} .
$$

Let $\alpha:[0,1] \times[0,1] \rightarrow \mathbb{R}^{+}$be defined as

$$
\alpha(x, y)=1+x+y,
$$


let $f: X \rightarrow X$ be defined as

$$
f(x)=\frac{1}{16} x^{2}
$$

and, let $\phi: \mathbb{R}^{+4} \rightarrow \mathbb{R}^{+}$denote

$$
\psi\left(t_{1}, t_{2}, t_{3}, t_{4}\right)=\frac{1}{2} \cdot \max \left\{t_{1}, t_{2}, t_{3}, \frac{1}{2} t_{4}\right\} .
$$

Then $f$ is $\alpha$-admissible.

Without loss of generality, we assume that $x>y$ and verify the inequality (2.1). For all $x, y \in[0,1]$ with $x>y$, we have

$$
\begin{aligned}
& \alpha(x, x) \alpha(y, y) p(f x, f y) \geq \frac{1}{16} x^{2}, \\
& p(x, y)=x, \quad p(x, f x)=x, \quad p(y, f y)=y \quad \text { and } \\
& \frac{1}{2}[p(x, f y)+p(y, f x)]=\frac{1}{2}\left[\max \left\{x, y^{2}\right\}+\max \left\{y, x^{2}\right\}\right] \\
& \leq \frac{1}{2}[\max \{x, y\}+\max \{y, x\}] \\
&<x,
\end{aligned}
$$

and hence $\phi\left(p(x, y), p(x, f x), p(y, f y), \frac{1}{2}[p(x, f y)+p(y, f x)]\right)=\frac{1}{2} x$. Therefore, all the conditions of Theorem 1 are satisfied, and we obtained that 0 is a fixed point of $f$.

If we let

$$
\alpha(x, y)=1 \quad \text { for } x, y \in X,
$$

then it is easy to get the following theorem.

Theorem 2 Let $(X, p)$ be a complete partial metric space and $\phi \in \Phi$. Suppose that $f: X \rightarrow$ $X$ is a generalized Meir-Keeler-type $\phi$-contraction. Then $f$ has a fixed point in $X$.

\section{Competing interests}

The authors declare that they have no competing interests.

\section{Authors' contributions}

All authors contributed equally and significantly in writing this article. All authors read and approved the final manuscript.

\section{Author details}

'Department of Applied Mathematics, Chung Yuan Christian University, Chungli, Taiwan. ${ }^{2}$ Department of Applied Mathematics, National Hsinchu University of Education, Hsinchu, Taiwan.

\section{Acknowledgements}

The authors would like to thank referee(s) for many useful comments and suggestions for the improvement of the paper. 


\section{References}

1. Mattews, SG: Partial metric topology. In: Proc. 8th Summer of Conference on General Topology and Applications. Ann. New York Acad. Sci., vol. 728, pp. 183-197 (1994)

2. Oltra, S, Valero, O: Banach's fixed point theorem for partial metric spaces. Rend. Ist. Mat. Univ. Trieste 36, 17-26 (2004)

3. Abdeljawad, T: Fixed points for generalized weakly contractive mappings in partial metric spaces. Math. Comput. Model. 54(11-12), 2923-2927 (2011)

4. Agarwal, RP, Alghamdi, MA, Shahzad, N: Fixed point theory for cyclic generalized contractions in partial metric spaces. Fixed Point Theory Appl. 2012, 40 (2012)

5. Altun, I, Erduran, A: Fixed point theorems for monotone mappings on partial metric spaces. Fixed Point Theory Appl. 2011, Article ID 508730 (2011)

6. Aydi, H: Fixed point results for weakly contractive mappings in ordered partial metric spaces. J. Adv. Math. Stud. 4(2), $1-12(2011)$

7. Chi, KP, Karapinar, E, Thanh, TD: A generalized contraction principle in partial metric spaces. Math. Comput. Model. 55(5-6), 1673-1681 (2012)

8. Karapinar, E: Weak $\phi$-contraction on partial metric spaces. J. Comput. Anal. Appl. 14(1), 206-210 (2012)

9. Karapinar, E: Generalizations of Caristi Kirk's theorem on partial metric spaces. Fixed Point Theory Appl. 2011, 4 (2011)

10. Karapinar, E, Erhan, IM: Fixed point theorem for cyclic maps on partial metric spaces. Appl. Math. Inf. Sci. 6, 239-244 (2012)

11. Meir, A, Keeler, E: A theorem on contraction mappings. J. Math. Anal. Appl. 28, 326-329 (1969)

12. Samet, B, Vetro, C, Vetro, P: Fixed point theorems for $\alpha$ - $\psi$-contractive type mappings. Nonlinear Anal. 75, 2154-2165 (2012)

doi:10.1186/1029-242X-2013-341

Cite this article as: Chen and Chen: Fixed point results for Meir-Keeler-type $\phi$ - $\alpha$-contractions on partial metric spaces. Journal of Inequalities and Applications 2013 2013:341.

\section{Submit your manuscript to a SpringerOpen ${ }^{\odot}$ journal and benefit from:}

- Convenient online submission

- Rigorous peer review

- Immediate publication on acceptance

Open access: articles freely available online

- High visibility within the field

- Retaining the copyright to your article 